\begin{tabular}{|c|l|}
\hline Title & Spatial diversity in gene expression for VDCCY subunit family in developing and adult mouse brains \\
\hline Author(s) & Fukaya, Masahiro; Y amazaki, May a; Sakimura, Kenji; W atanabe, Masahiko \\
\hline Citation & $\begin{array}{l}\text { Neuroscience Research, 53(4), 376-383 } \\
\text { https://doi.org/40.1016/.neures.2005.08.009 }\end{array}$ \\
\hline Issue Date & $2005-09$-19 \\
\hline Doc URL & http://hdl.handle.net/2115/934 \\
\hline Type & article(author version) \\
\hline File Information & NR53-4.pdf \\
\hline
\end{tabular}

Instructions for use 


\section{Spatial diversity in gene expression for VDCC $\gamma$ subunit family in developing and adult mouse brains}

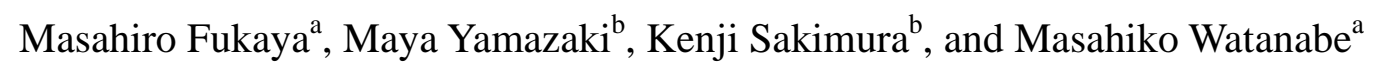

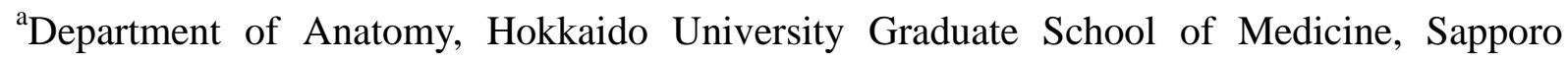
060-8638, Japan

${ }^{\mathrm{b}}$ Department of Cellular Neurobiology, Brain Research Institute, Niigata University, Niigata 951-8122, Japan

The total number of pages (25), Figures (4), and Table (1)

Correspondence to: Masahiro Fukaya

Department of Anatomy

Hokkaido University Graduate School of Medicine

Sapporo 060-8638, Japan

TEL, +81-11-706-5030; FAX, +81-11-706-5031

E-mail,mfukaya@med.hokukdai.ac.jp 


\section{Abstract}

The $\gamma$ subunit of voltage-dependent $\mathrm{Ca}^{2+}$ channels (VDCCs) is characterized by molecular diversity and regulation of AMPA-type glutamate receptors as well as VDCCs. In the present study, we examined expressions for the VDCC $\gamma 1-8$ subunit mRNAs in developing and adult mouse brains by in situ hybridization. In adult brains, the $\gamma 2$ and $\gamma 7$ subunit mRNAs were widely expressed in various grey matter regions with the highest level in cerebellar Purkinje cells and granule cells. The $\gamma 3$ and $\gamma 8$ subunit mRNAs predominated in the telencephalon, with the latter being at striking levels in the hippocampus. The $\gamma 4$ subunit mRNA was enriched in the olfactory bulb, striatum, thalamus, and hypothalamus. The $\gamma 5$ subunit mRNA was abundant in the olfactory bulb, hippocampal CA2, thalamus, inferior colliculus, and Bergmann glia. Transcripts of these subunits were detected in embryonic brains: some showed well-preserved spatial patterns ( $\gamma 2, \gamma 5, \gamma 7$ and $\gamma 8)$, while others underwent developmental up$(\gamma 3)$ or down-regulation $(\gamma 4)$. In contrast, the $\gamma 1$ and $\gamma 6$ subunit mRNAs were negative or very low throughout brain development. Therefore the present study has revealed spatial diversity in gene expression for individual VDCC $\gamma$ subunits, presumably reflecting functional diversity of this protein family and their differential involvement in neural function.

Key words: VDCC $\gamma$ subunit, Stargazin, TARPs, Development, mRNA, In situ hybridization, Brain. 


\section{Introduction}

The $\gamma$ subunit of voltage-dependent $\mathrm{Ca}^{2+}$ channels (VDCCs) has been originally identified as an auxiliary subunit of 1,4-dihydropyridine (DHP)-sensitive or L-type VDCCs in skeletal muscles (Bosse et al., 1990; Jay et al., 1990; Powers et al., 1993). The second subunit, $\gamma 2$ subunit or stargazin, was identified as a gene responsible for the spontaneous mutant mouse, stargazer, which is characterized by absence epilepsy and ataxia (Letts et al., 1998). Subsequent studies have revealed six additional subunits and, hence, there are eight members to date in the VDCC $\gamma$ family (Black and Lennon., 1999; Burgess et al., 1999, 2001; Klugbauer et al., 2000; Chu et al., 2001; Moss et al., 2002). Each $\gamma$ subunit contains four putative transmembrane domains with intracellularly located $\mathrm{N}$ - and C-termini (Chu et al., 2001; Black, 2003). The $\gamma 1, \gamma 2, \gamma 3, \gamma 4, \gamma 5$, and $\gamma 7$ subunits have been shown to affect the function of L-type, T-type, and P/Q-type VDCCs, when expressed in various combinations (Wei et al., 1991; Eberst et al., 1997; Letts et al., 1998; Klugbauer et al., 2000; Freise et al., 2000; Rousset et al., 2001; Green et al., 2001; Moss et al., 2002, Held et al., 2002). On the other hand, the $\gamma 2$ subunit and its structurally-related members, $\gamma 3, \gamma 4$, and $\gamma 8$ subunits, are crucial for cell surface expression, synaptic targeting, recycling, channel activity, and gating of $\alpha$-amino-3-hydroxy-5-methyl-4-isoxazolepropionic acid (AMPA) receptors, and hence named as transmembrane AMPA receptor regulatory proteins (TARPs) (Chen et al., 2000; Tomita et al., 2003, 2004, 2005; Yamazaki et al., 2004; Priel et al., 2005). The $\gamma$ subunit family is expressed in various tissues, including the brain, skeletal muscle, heart, lung, and testis (Chu et al., 2001). In the brain, all $\gamma$ subunits, except the $\gamma 1$ subunit, are expressed (Chu et al., 2001). Of these, four TARPs have been reported to display high and distinct expressions 
in the developing and adult brains (Klugbauer et al., 2000; Chen et al., 2000; Tomita et al., 2003). However, comparative and systematic analysis on the expression of the VDCC $\gamma$ family has not yet been performed. In the present study, we examined expressions for the VDCC $\gamma 1-8$ subunit mRNAs in developing and adult mouse brains by in situ hybridization with $\left[{ }^{33} \mathrm{P}\right] \mathrm{dATP}-\mathrm{labeled}$ antisense oligonucleotide probes, and have revealed their distinct regional and cellular expression in the brain.

\section{Materials and Methods}

\section{Probes}

To detect mRNAs for each VDCC $\gamma$ subunit, specific antisense oligonucleotide probes were synthesized as follows: 5'-gtgctctggctcagcgtccatgcaggattcccaggggttctgagg-3' for the $\gamma 1$ subunit (GenBank accession $\quad$ No. 5'-gatgcgggtgatggcggaggcctggaggtagtcggtggcgcgggc-3' for the $\gamma 2$ subunit (accession No. AF077739), 5'-cggcaggcgcgcaaatgtagacttcttcaggagctctgaatggga-3' for the $\gamma 3$ subunit (accession No. AJ272044), 5'-ggcgtaaggagaggaggaagaggccttaaggaactcccgcttggt-3' for the $\begin{array}{llll}\gamma 4 & \text { subunit } & \text { (accession } & \text { No. }\end{array}$ 5'-catctggtcatagtctgggcacttgagcaaagctgggtagttgct-3' for the $\gamma 5$ subunit (accession No. AF361347), 5'-ttgggccacccacttggggcacagtgacctccagggccaggaag-3' for the $\gamma 6$ subunit (accession No. AF361348), 5'-gcgatagtgaaagtactgctcagagctgctgggcctgttcat-3' for the $\gamma 7$ $\begin{array}{llll}\text { subunit } \quad \text { (accession } & \text { No. } & \text { AF361349), }\end{array}$ 5'-acaccacaaacccctctcttcattccagcgtttcaatgactccag-3' for the $\gamma 8$ subunit (accession No. 
AF361350). Oligonucleotide probes were labeled with $\left[{ }^{33} \mathrm{P}\right] \mathrm{dATP}$ using terminal deoxyribonucleotidyl transferase (Invitrogen, Carlsbad, CA).

In situ hybridization

Under deep pentobarbital anesthesia, the brains were freshly obtained from C57BL/6J mice at embryonic days 13 (E13), E18, postnatal days 1 (P1), P7, P14, P21, and adult (4 months). The day after overnight mating was designated as E0, and the day of birth as P1. Fresh frozen sections (20 $\mu \mathrm{m}$ thickness) were cut with a cryostat (CM1900, Leica, Nussloch, Germany) and mounted on glass slides precoated with 3-aminopropyltriethoxysilane. Probe labeling and hybridization were performed as described (Fukaya et al., 2005) with minor modifications. Sections were treated at room temperature with the following incubation steps: fixation with $4 \%$ paraformaldehyde-0.1M sodium phosphate buffer ( $\mathrm{pH} 7.2$ ) for $10 \mathrm{~min}, 2 \mathrm{mg} / \mathrm{ml}$ glycine-phosphate-buffered saline $(\mathrm{pH} 7.2)$ for $10 \mathrm{~min}$, acetylation with $0.25 \%$ acetic anhydride in $0.1 \mathrm{M}$ triethanolamine- $\mathrm{HCl}(\mathrm{pH}$ 8.0) for $10 \mathrm{~min}$, and prehybridization for 1 hr in a buffer containing 50\% formamide, $50 \mathrm{mM}$ Tris- $\mathrm{HCl}(\mathrm{pH} 7.5), 0.02 \%$ Ficoll, 0.02\% polyvinylpyrrolidone, $0.02 \%$ bovine serum albumin, $0.6 \mathrm{M} \mathrm{NaCl}, 0.25 \%$ SDS, $200 \mu \mathrm{g} / \mathrm{ml}$ tRNA, $1 \mathrm{mM}$ EDTA, and 10\% dextran sulfate. Hybridization was performed at $42{ }^{\circ} \mathrm{C}$ for $12 \mathrm{hr}$ in the prehybridization buffer supplemented with $10,000 \mathrm{cpm} / \mu \mathrm{l}$ of $\left[{ }^{33} \mathrm{P}\right] \mathrm{dATP}-$ labeled oligonucleotides. Slides were washed twice at $55{ }^{\circ} \mathrm{C}$ for $40 \mathrm{~min}$ in 0.1 x SSC containing $0.1 \%$ sarcosyl. Sections were exposed either to BioMax (Kodak, Rochester, NY) or to Nuclear Track emulsion (NTB-2, Kodak) for 4 weeks. Emulsion-dipped sections were Nissl-stained with methyl green pyronine solution. 


\section{Results}

In situ hybridization was employed to reveal the spatiotemporal expression patterns of each VDCC $\gamma$ subunit mRNA in the mouse brain using radiolabeled antisense oligonucleotide probes. Overall distribution was examined by X-ray film macroautoradiography (Fig. 1), while detailed regional and cellular expression was determined by emulsion microautoradiography (Fig. 2, 3). The specificity of hybridizing signals was verified by the disappearance of signals when hybridization was carried out in the presence of a 100-fold excess amount of unlabeled oligonucleotides (Fig. 1A-H insets).

\section{Distribution in adult mouse brain}

Regional and cellular expressions in the cerebral cortex, hippocampus, and cerebellum are mainly described in the text, and expressions in other regions are summarized in Table 1.

$\gamma 1$ subunit. No significant signals for the $\gamma 1$ subunit mRNA were detected in any regions of the adult brain (Fig. 1A, 2A, 2I, 2Q).

$\gamma 2$ subunit. The $\gamma 2$ subunit mRNA was detected at high levels in various grey matter regions (Fig 1B). The highest expression was found in the cerebellar cortex, where the $\gamma 2$ subunit mRNA was expressed strongly in Purkinje cells and granule cells, and moderately in the molecular layer neurons (basket and stellate cells) and deep cerebellar nuclei (Fig. 2R, 3M). In the cerebral cortex, the $\gamma 2$ subunit mRNA was distributed in layers II-VI (Fig. 2B). In the hippocampus, it was detected strongly in pyramidal cell layer of the CA3 region and 
granule cell layer of the dentate gyrus, and weakly in CA1 pyramidal cell layer (Fig. 1B, 2J, 3A, 3G). Intense signals were also detected in neurons of polymorphic layer of the dentate gyrus and interneurons dispersed in the CA1 region (Fig. 2J, 3A, 3G).

$\gamma 3$ subunit. Hybridization signals for the $\gamma 3$ subunit mRNA were predominantly detected in the telencephalon, including the olfactory bulb, cerebral cortex, hippocampus, striatum, septum, and amygdala (Fig. 1C). In the hippocampus, the $\gamma 3$ subunit mRNA was intense in CA1 pyramidal cell layer, moderate in CA3 pyramidal cell layer and granule cell layer of the dentate gyrus, and very low in the CA2 region (Fig. 2K, 3B, 3H). Expression was low in lower brain regions, including the cerebellum (Fig. 1C). Emulsion microautoradiography revealed the presence of dispersed signal clusters in the cerebellum, which originated from large cells dispersed in the granular layer, i.e., Golgi cells, an interneuron in the granular layer (Fig. 2S, 3N).

$\gamma 4$ subunit. Hybridization signals for the $\gamma 4$ subunit mRNA were found in various brain regions with higher levels in the olfactory bulb, striatum, thalamus, and hypothalamus (Fig. 1D). In these regions, signals were detected in major cellular populations. For example, most cells were labeled in thalamic nuclei. In other regions, the $\gamma 4$ subunit mRNA was expressed in limited cellular populations, which were poorly labeled with Nissl staining and distributed irrespective of the grey and white matters (Fig. 2D, 2L, 2T, 3C, 3I). Moreover, laminar patterns of signal distribution were obscure in the cerebral cortex and hippocampus, suggesting its expression in non-neuronal cells. In the cerebellum, high levels of the $\gamma 4$ subunit mRNA were detected in the Purkinje cell layer (Fig. 2T), where it was detected in Bergmann glia, but not in Purkinje cells (Fig. 30). 
$\gamma 5$ subunit. The $\gamma 5$ subunit mRNA was detected highly in the olfactory bulb, CA2 region of the hippocampus, thalamus, and cerebellum, and moderately in the septum and inferior colliculus (Fig. 1E). In the hippocampal CA2 region, signals for the $\gamma 5$ subunit mRNA were detected over pyramidal cells, (Fig. 2M, 3D). In the cerebellum, the $\gamma 5$ subunit mRNA was selectively expressed in Bergmann glia (Fig. 2U, 3P).

$\gamma 6$ subunit. Hybridization signals for the $\gamma 6$ subunit mRNA were very low in the adult brain, showing faint labeling in some telencephalic structures, such as the olfactory bulb and hippocampus (Fig. 1F, 2F, 2N, 2V).

$\gamma 7$ subunit. The $\gamma 7$ subunit mRNA was prominently expressed in various grey matter regions (Fig. 1G). In the cerebral cortex, moderate levels were observed in the layers II-VI (Fig. 2G). In the hippocampus, levels were higher in the CA2 region and dentate gyrus than in the CA1 and CA3 regions (Fig. 2O, 3E, 3K). In the cerebellum, the $\gamma 7$ subunit mRNA was high in Purkinje cells, and also detected in other neurons, including granule cells, molecular layer interneurons, and neurons in the deep cerebellar nuclei (Fig. 2W, 3Q).

$\gamma 8$ subunit. The $\gamma 8$ subunit mRNA was highly enriched in the telencephalon with the highest levels in all hippocampal regions (Fig. 1H, 2P, 3F, 3L). In the cerebral cortex, levels were higher in the layers II/III and V than the layers IV and VI (Fig. 2H).

\section{Developmental changes}

Developmental changes were examined from E13 to P21 (Fig. 4). VDCC $\gamma$ subunits that were expresssed highly in the adult brain (i.e., $\gamma 2-5, \gamma 7, \gamma 8$ ) also exhibited high expression in embryonic brains. Of these, several subunits showed generally preserved patterns of spatial 
expression throughout development. Higher expression of the $\gamma 2$ subunit mRNA in the cerebellum (Fig. 4B), wide expression of the $\gamma 7$ subunit mRNA in the brain (Fig. 4G), and higher expression of the $\gamma 8$ subunit mRNA in the telencephalon (Fig. $4 \mathrm{H}$ ) were all noted from embryonic and neonatal stages, and continued to the adult stage. In addition, higher expression of the $\gamma 5$ subunit mRNA in the olfactory bulb, thalamus, inferior colliculus, and cerebellar cortex was observed from perinatal stages (Fig. 4E). On the other hand, the $\gamma 4$ subunit mRNA was very strong throughout brains until P7, and the adult type of expression was established by thereafter downregulation in the grey matter, except for olfactory bulb, striatum, and thalamus (Fig. 4D). On the contrary, higher expression of the $\gamma 3$ subunit mRNA in the telencephalon became apparent at P7 and thereafter (Fig. 4C).

Faint signals for the $\gamma 1$ subunit mRNA was transiently detected in the telencephalon at E18 and P1 (Fig. 4A). At P7, low signals for $\gamma 6$ subunit mRNA first appeared in the olfactory bulb, cerebral cortex, and hippocampus, which was maintained until the adult stage (Fig. 4F). In contrast to generally low expression in the brain, the $\gamma 1$ and $\gamma 6$ subunit mRNAs were clearly detected in the skeletal muscle (arrows in Fig. 4A, F).

\section{Discussion}

In the present study, we examined expression patterns for the VDCC $\gamma$ subunit family in developing and adult mouse brains by in situ hybridization, and have disclosed their distinct regional and cellular expression as summarized in Table 1. 
The TARP family, which consists of $\gamma 2, \gamma 3, \gamma 4$, and $\gamma 8$ subunits, was originally reported to participate in surface expression, synaptic targeting and recycling of AMPA receptors (Chen et al., 2000; Tomita et al., 2003, 2004). Recently, we and others have found that TARPs not only modulate AMPA receptor trafficking but also regulate their channel activities working as auxiliary subunits (Yamazaki et al., 2004; Priel et al., 2005; Tomita et al., 2005). Therefore, the TARP family, presumably other VDCC $\gamma$ subunits as well, play diverse roles as ion channel modulators. Distinct regional expressions of the TARP-VDCC $\gamma$ subunits in the present study are well consistent with previous reports (Chen et al., 2000; Klugbauer at al., 2000; Tomita et al., 2003). In general, major subunits in given brain regions are $\gamma 2, \gamma 3$, and $\gamma 8$ subunits in the telencephalon, $\gamma 2$ and $\gamma 4$ subunits in the diencephalon, and $\gamma 2$ subunit in other regions, including the cerebellum. Within the cerebellum, we have disclosed here distinct cellular expression: $\gamma 2$ subunit in Purkinje cells, granule cells and molecular layer interneurons, $\gamma 3$ subunit in Golgi cells, and $\gamma 4$ subunit in Bergmann glia. The distinct cellular expression agrees with reported phenotypes in the stargazer mouse, a spontaneous mutant defective in the $\gamma 2$ subunit (Letts et al., 1998). In the stargazer cerebellum, AMPA receptor-mediated fast responses are almost missing and AMPA receptor subunits are greatly reduced at mossy fiber-granule cell synapses (Hashimoto et al., 1999; Chen et al., 1999, 2000). On the other hand, AMPA receptors at hippocampal pyramidal cell synapses are intact in the stargazer mouse (Hashimoto et al., 1999). Based on our present results, this different phenotype can be interpreted that the $\gamma 2$ subunit is the sole subunit of the TARPs expressed in cerebellar granule cells, whereas it is one of the subunits expressed in hippocampal pyramidal cells. In particular, the $\gamma 8$ subunit is expressed most prominently in the hippocampus, and thus may compensate 
the loss of $\gamma 2$ subunit function in the stargazer (Fig. $1 \mathrm{H}$ and $2 \mathrm{P}$ in the present study; Tomita et al., 2003). If this is also true for other neurons, AMPA receptor function and localization might be greatly affected at synapses in cerebellar Purkinje cells and brainstem motoneurons of the stargazer, in which the $\gamma 2$ subunit is predominantly expressed, like cerebellar granule cells. Since $\mathrm{Ca}^{2+}$-permeable AMPA receptors expressed in Bergmann glia have been shown to play an important role in glial enwrapping of Purkinje cell synapses (Iino et al., 2001), the $\gamma 4$ subunit may also control transmission at Purkinje cell synapses through regulating the glial AMPA receptors.

Regional and cellular distributions of mRNAs for non-TARP-VDCC $\gamma$ subunits $(\gamma 1, \gamma 5$, $\gamma 6$, and $\gamma 7$ subunits) are also differential in the brain. Of these, the $\gamma 1, \gamma 5$ and $\gamma 7$ subunits are known to regulate function and localization of VDCC complex (Wei et al., 1991; Eberst et al., 1997; Klugbauer et al., 2000; Moss et al., 2002). Although the $\gamma 1$ and $\gamma 6$ subunit mRNA are expressed in skeletal muscles (Fig. 4A, 4F; Powers et al., 1993), they are negative or showed low restricted expression in the adult brain, suggesting little or limited contribution to brain function. Transient expression of the $\gamma 1$ subunit mRNA in newborn telencephalon implies its transient involvement in brain development. In contrast, the $\gamma 7$ subunit mRNA is expressed highly and widely in developing and adult brains, suggesting that it is a major regulator for VDCCs in the brain. From the expression in particular neural regions, such as hippocampal CA2 region and Bergmann glia, the $\gamma 5$ subunit may play some additional role in these regions. Functional assignment of the $\gamma 6$ subunit remains unknown, and its expression in the brain is low throughout development.

The VDCC $\gamma$ subunit family is thus diverse not only in molecular forms and function, 
but also in their spatial expression in the brain. The present mapping study on the VDCC $\gamma$ subunits will provide the molecular-anatomical basis for future studies.

\section{Acknowledgement}

This investigation was supported by Grants-in-Aid for Scientific Research (A, B) (MW), for Scientific Research on Priority Areas (MW), and for Young Scientists (B) (MF) provided by the Ministry of Education, Culture, Sports, Science and Technology of Japan. 


\section{References}

Black JL III (2003) The voltage-gated calcium channel gamma subunits: a review of the literature. J Bioenerg Biomembr 35:649-660.

Black JL III, Lennon VA (1999) Identification and cloning of putative human neuronal voltage-gated calcium channel gamma-2 and gamma-3 subunits: neurologic implications. Mayo Clin Proc 74:357-361.

Bosse E, Regulla S, Biel M, Ruth P, Meyer HE, Flockerzi V, Hofmann F (1990) The cDNA and deduced amino acid sequence of the gamma subunit of the L-type calcium channel from rabbit skeletal muscle. FEBS Lett 267:153-156.

Burgess DL, Davis CF, Gefrides LA, Noebels JL (1999) Identification of three novel $\mathrm{Ca}^{2+}$ channel gamma subunit genes reveals molecular diversification by tandem and chromosome duplication. Genome Res 9:1204-1213.

Burgess DL, Gefrides LA, Foreman PJ, Noebels JL (2001) A Cluster of Three Novel Ca ${ }^{2+}$ Channel gamma Subunit Genes on Chromosome 19q13.4: Evolution and Expression Profile of the gamma Subunit Gene Family. Genomics 71:339-350.

Chen L, Bao S, Qiao X, Thompson RF (1999) Impaired cerebellar synapse maturation in waggler, a mutant mouse with a disrupted neuronal calcium channel gamma subunit. Proc 
Natl Acad Sci U S A 96:12132-12137.

Chen L, Chetkovich DM, Petralia RS, Sweeney NT, Kawasaki Y, Wenthold RJ, Bredt DS, Nicoll RA (2000) Stargazin regulates synaptic targeting of AMPA receptors by two distinct mechanisms. Nature 408:936-943.

Chu PJ, Robertson HM, Best PM (2001) Calcium channel gamma subunits provide insights into the evolution of this gene family. Gene 280:37-48.

Eberst R, Dai S, Klugbauer N, Hofmann F (1997) Identification and functional characterization of a calcium channel gamma subunit. Pflugers Arch 433:633-637.

Freise D, Held B, Wissenbach U, Pfeifer A, Trost C, Himmerkus N, Schweig U, Freichel M, Biel M, Hofmann F, Hoth M, Flockerzi V (2000) Absence of the gamma subunit of the skeletal muscle dihydropyridine receptor increases L-type $\mathrm{Ca}^{2+}$ currents and alters channel inactivation properties. J Biol Chem 275:14476-14481.

Fukaya M, Hayashi Y, Watanabe M (2005) NR2 to NR3B subunit switchover of NMDA receptors in early postnatal motoneurons. Eur J Neurosci 21:1432-1436.

Green PJ, Warre R, Hayes PD, McNaughton NC, Medhurst AD, Pangalos M, Duckworth DM, Randall AD (2001) Kinetic modification of the $\alpha 1$ I subunit-mediated T-type $\mathrm{Ca}^{2+}$ channel by 
a human neuronal $\mathrm{Ca}^{2+}$ channel gamma subunit. J Physiol 533:467-478.

Hashimoto K, Fukaya M, Qiao X, Sakimura K, Watanabe M, Kano M (1999) Impairment of AMPA receptor function in cerebellar granule cells of ataxic mutant mouse stargazer. $\mathrm{J}$ Neurosci 19:6027-6036.

Held B, Freise D, Freichel M, Hoth M, Flockerzi V (2002) Skeletal muscle L-type $\mathrm{Ca}^{2+}$ current modulation in gamma1-deficient and wildtype murine myotubes by the gamma1 subunit and cAMP. J Physiol 539:459-468.

Iino M, Goto K, Kakegawa W, Okado H, Sudo M, Ishiuchi S, Miwa A, Takayasu Y, Saito I, Tsuzuki K, Ozawa S (2001) Glia-synapse interaction through $\mathrm{Ca}^{2+}$-permeable AMPA receptors in Bergmann glia. Science 292:926-929.

Jay SD, Ellis SB, McCue AF, Williams ME, Vedvick TS, Harpold MM, Campbell KP (1990) Primary structure of the gamma subunit of the DHP-sensitive calcium channel from skeletal muscle. Science 248:490-492.

Klugbauer N, Dai S, Specht V, Lacinova L, Marais E, Bohn G, Hofmann F (2000) A family of gamma-like calcium channel subunits. FEBS Lett 470:189-197.

Letts VA, Felix R, Biddlecome GH, Arikkath J, Mahaffey CL, Valenzuela A, Bartlett FS II, 
Mori Y, Campbell KP, Frankel WN (1998) The mouse stargazer gene encodes a neuronal $\mathrm{Ca}^{2+}$-channel gamma subunit. Nat Genet 19:340-347.

Moss FJ, Viard P, Davies A, Bertaso F, Page KM, Graham A, Canti C, Plumpton M, Plumpton C, Clare JJ, Dolphin AC (2002) The novel product of a five-exon stargazin-related gene abolishes CaV2.2 calcium channel expression. Embo J 21:1514-1523.

Powers PA, Liu S, Hogan K, Gregg RG (1993) Molecular characterization of the gene encoding the gamma subunit of the human skeletal muscle 1,4-dihydropyridine-sensitive $\mathrm{Ca}^{2+}$ channel (CACNLG), cDNA sequence, gene structure, and chromosomal location. J Biol Chem 268:9275-9279.

Priel A, Kolleker A, Ayalon G, Gillor M, Osten P, Stern-Bach Y (2005) Stargazin reduces desensitization and slows deactivation of the AMPA-type glutamate receptors. J Neurosci 25:2682-2686.

Rousset M, Cens T, Restituito S, Barrere C, Black JL III, McEnery MW, Charnet P (2001) Functional roles of gamma2, gamma3 and gamma4, three new $\mathrm{Ca}^{2+}$ channel subunits, in P/Q-type $\mathrm{Ca}^{2+}$ channel expressed in Xenopus oocytes. J Physiol 532:583-593.

Tomita S, Chen L, Kawasaki Y, Petralia RS, Wenthold RJ, Nicoll RA, Bredt DS (2003) Functional studies and distribution define a family of transmembrane AMPA receptor 
regulatory proteins. J Cell Biol 161:805-816.

Tomita S, Fukata M, Nicoll RA, Bredt DS (2004) Dynamic interaction of stargazin-like TARPs with cycling AMPA receptors at synapses. Science 303:1508-1511.

Tomita S, Adesnik H, Sekiguchi M, Zhang W, Wada K, Howe JR, Nicoll RA, Bredt DS (2005) Stargazin modulates AMPA receptor gating and trafficking by distinct domains. Nature 435: 1052-1058.

Wei XY, Perez-Reyes E, Lacerda AE, Schuster G, Brown AM, Birnbaumer L (1991) Heterologous regulation of the cardiac $\mathrm{Ca}^{2+}$ channel $\alpha 1$ subunit by skeletal muscle $\beta$ and $\gamma$ subunits. Implications for the structure of cardiac L-type $\mathrm{Ca}^{2+}$ channels. J Biol Chem 266:21943-21947.

Yamazaki M, Ohno-Shosaku T, Fukaya M, Kano M, Watanabe M, Sakimura K (2004) A novel action of stargazin as an enhancer of AMPA receptor activity. Neurosci Res 50:369-374. 


\section{Legends}

Figure 1. Distribution of VDCC $\gamma 1$ (A), $\gamma 2$ (B), $\gamma 3$ (C), $\gamma 4$ (D), $\gamma 5$ (E), $\gamma 6$ (F), $\gamma 7$ (G), and $\gamma 8$ $(\mathrm{H})$ subunit mRNAs in the adult mouse brain. Images were made from parasagittal brain sections exposed to an X-ray film. Insets show negative hybridizing signals by adding unlabeled probes. Cb, cerebellum; CP, caudate-putamen; Cx, cerebral cortex; Hi, hippocampus; Hy, hypothalamus; Mb, midbrain; MO, medulla oblongata; OB, olfactory bulb; Th, thalamus. Scale bars, $1 \mathrm{~mm}$.

Figure 2. Distribution of VDCC $\gamma 1$ (A, I, Q), $\gamma 2$ (B, J, R), $\gamma 3$ (C, K, S), $\gamma 4$ (D, L, T), $\gamma 5$ (E, M, $\mathrm{U}), \gamma 6(\mathrm{~F}, \mathrm{~N}, \mathrm{~V}), \gamma 7(\mathrm{G}, \mathrm{O}, \mathrm{W})$, and $\gamma 8(\mathrm{H}, \mathrm{P}, \mathrm{X})$ subunit mRNAs in the adult cerebral cortex (A-H), hippocampus (I-P), and cerebellum (Q-X). Images were made from emulsion-dipped sections. CA1-3, CA1-3 regions of the hippocampus; CC, corpus callosum; CP, caudate-putamen; DCN, deep cerebellar nuclei; DG, dentate gyrus; GL, granular rayer; I-VI, layer I-VI of the cerebral cortex; ML, molecular layer; PL, Purkinje cell layer; Su, subiculum. Scale bars, $500 \mu \mathrm{m}$ in A and I; $1 \mathrm{~mm}$ in Q.

Figure 3. Bright-field miscrographs showing VDCC $\gamma 2$ (A, G, M), $\gamma 3(B, H, N), \gamma 4(C, I, O)$, $\gamma 5$ (D, J, P), $\gamma 7$ (E, K, Q), and $\gamma 8$ (F, L, R) subunit mRNAs in the adult hippocampal CA1 or CA2 region (A-F), dentate gyrus (G-L), and cerebellar cortex (M-R). No significant signals for the $\gamma 1$ and $\gamma 6$ subunit mRNAs were detected in emulsion-dipped sections. White arrowheads in C and I indicate $\gamma 4$ mRNA-positive glial cells. Black and white arrows in M-R indicate the cell body of Purkinje cells and Bergmann glia, respectively. Double arrows in $\mathrm{N}$ 
indicate a Golgi cell. CA1 and CA2, CA1 and CA2 regions of the hippocampus; Cb, cerebellum; DG, dentate gyrus; Gr, granular layer; Mo, molecular layer; Or, stratum oriens; Po, polymorphic layer; Py, pyramidal cell layer; Ra, stratum radiatum. Scale bars, $20 \mu \mathrm{m}$.

Figure 4. Developmental changes in expressions for VDCC $\gamma 1$ (A), $\gamma 2$ (B), $\gamma 3$ (C), $\gamma 4$ (D), $\gamma 5$ (E), $\gamma 6(\mathrm{~F}), \gamma 7(\mathrm{G})$, and $\gamma 8(\mathrm{H})$ mRNAs in mouse brains from E13 to P21. Each set of hybridized sections was exposed to a single X-ray film. Arrows indicate expression of $\gamma 1$ and $\gamma 2$ mRNAs in the skeletal muscles. Scale bar, $1 \mathrm{~mm}$. 
Fukaya et al. 20

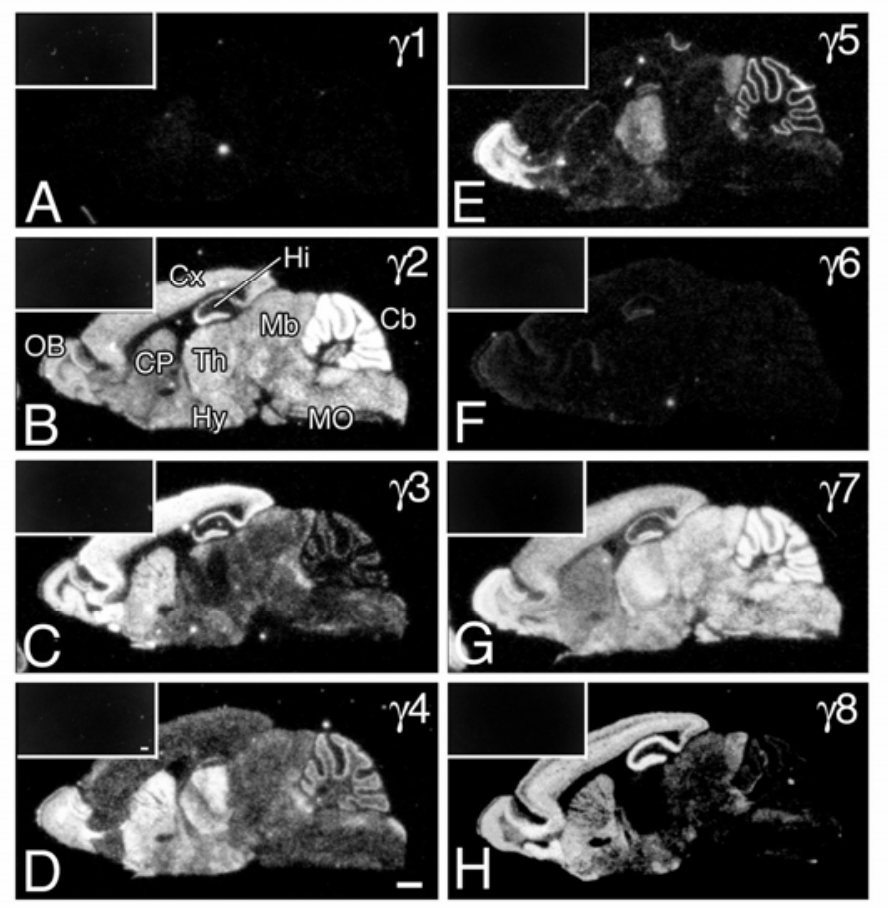

Fukaya et al.

Figure 1 

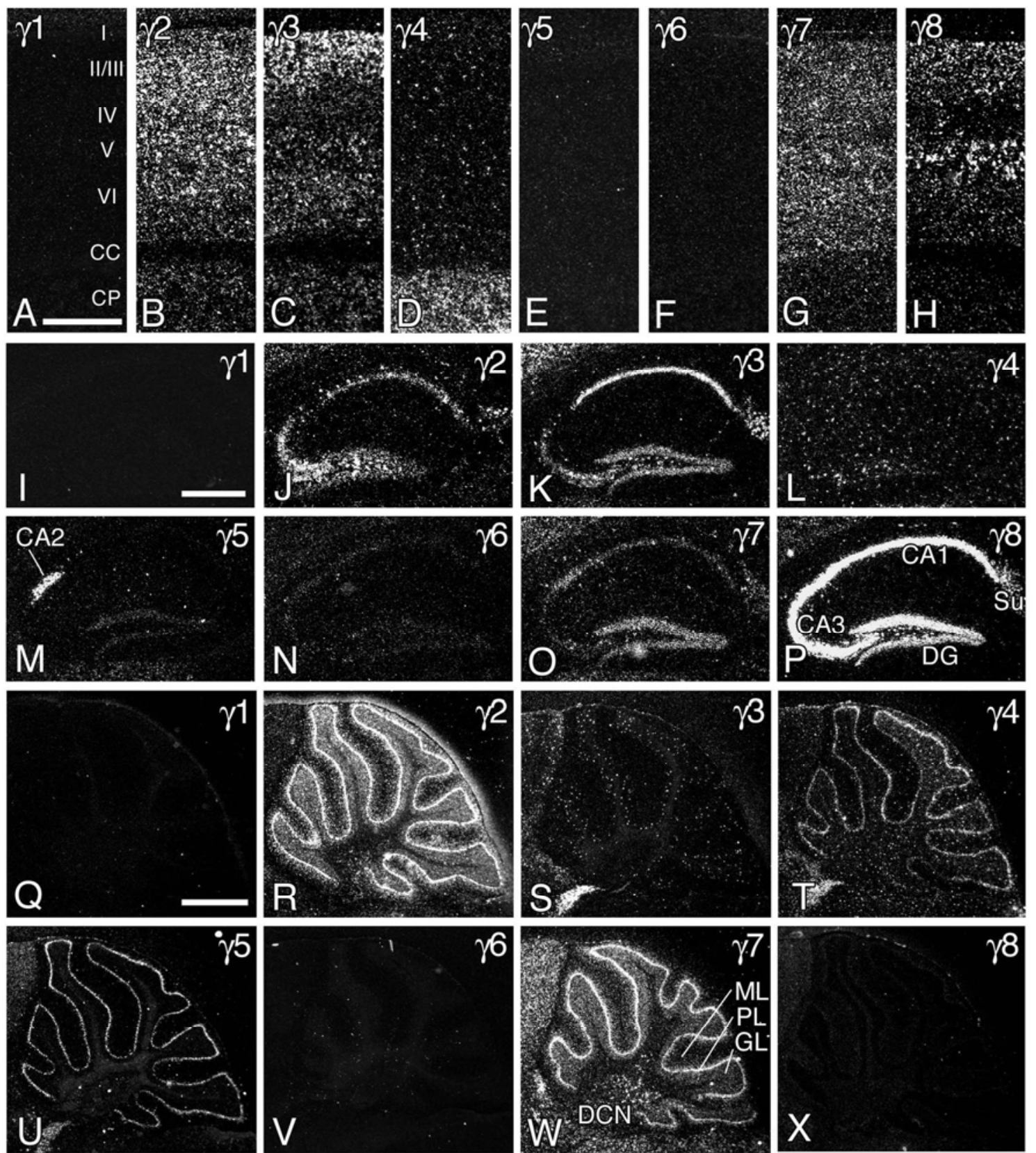

$\gamma 8$

Fukaya et al.

Figure 2 
Fukaya et al. 22

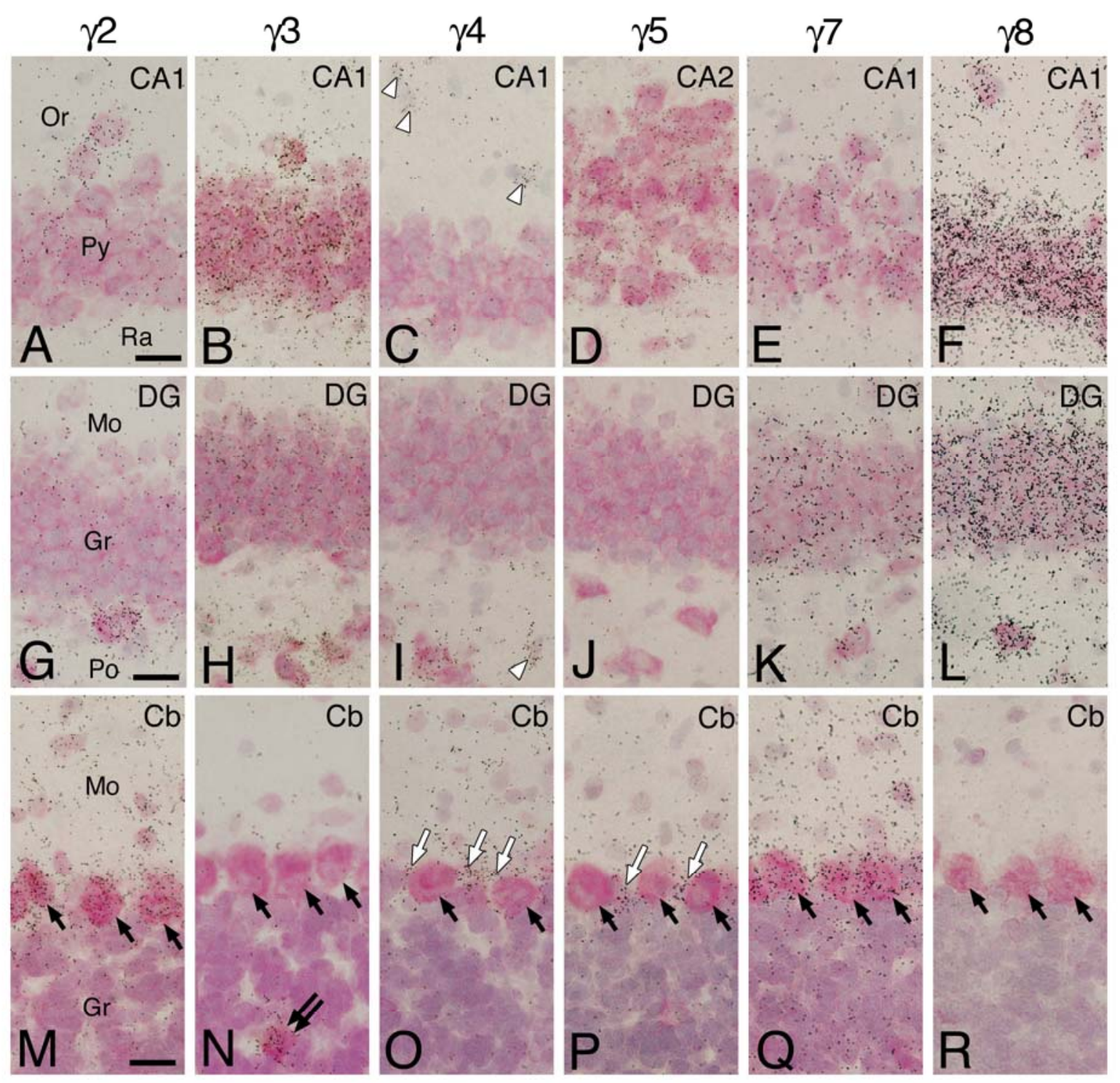

Fukaya et al.

Figure 3 


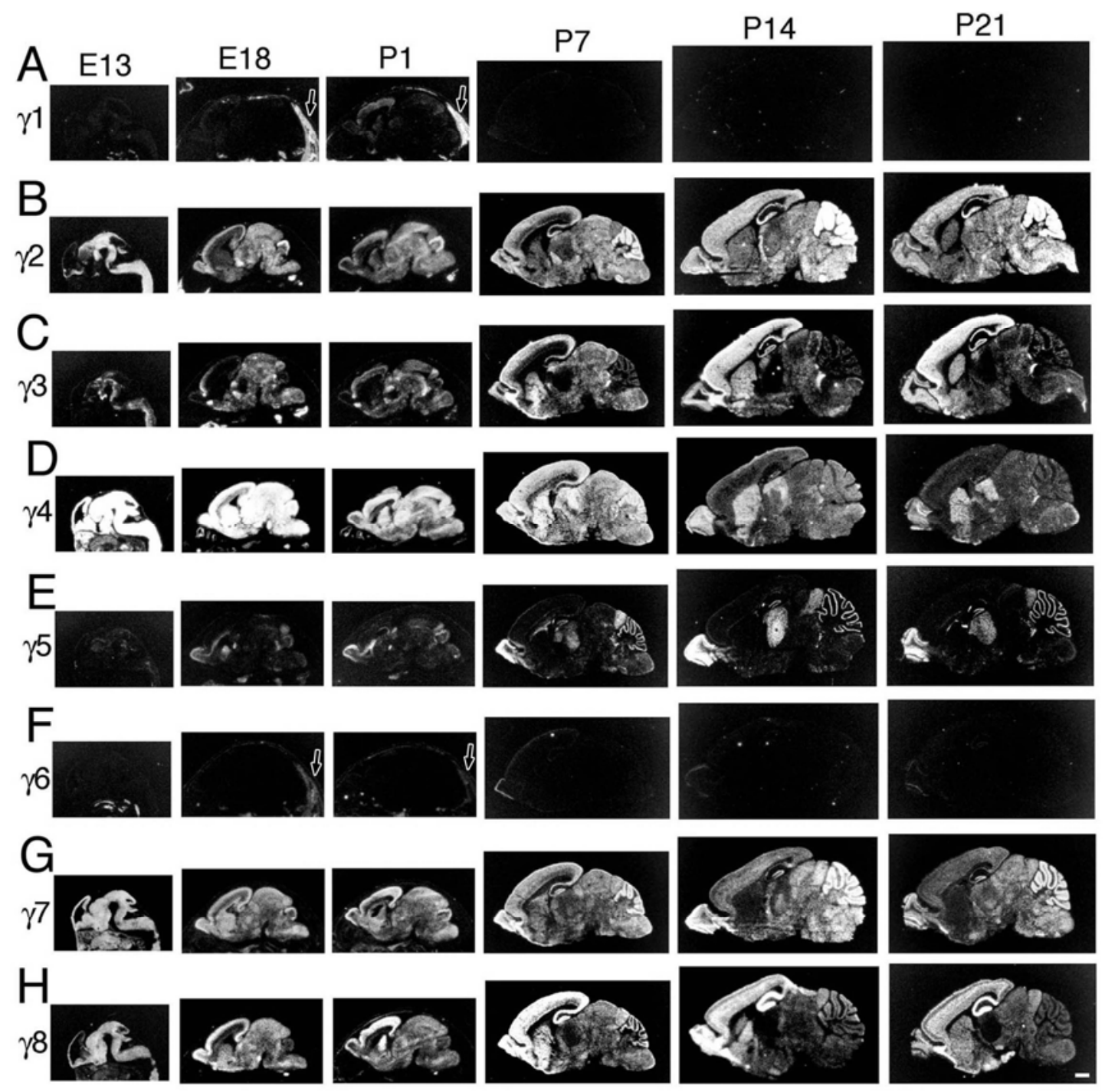

Fukaya et al.

Figure 4 
Table 1. Relative abundance $*^{1}$ of VDCC $\gamma$ subunit mRNAs in adult mouse brain

\begin{tabular}{|c|c|c|c|c|c|c|c|c|}
\hline & $\gamma 1$ & $\gamma 2$ & $\gamma 3$ & $\gamma 4$ & $\gamma 5$ & $\gamma 6$ & $\gamma 7$ & $\gamma 8$ \\
\hline \multicolumn{9}{|l|}{ Olfactory bulb } \\
\hline Mitral cell layer & - & 1 & 1 & 1 & 4 & 2 & 4 & 1 \\
\hline Granule cell layer & - & 3 & 4 & 4 & 4 & 2 & 4 & 4 \\
\hline Glomerular layer & - & 3 & 1 & 4 & 4 & 2 & 4 & 3 \\
\hline \multicolumn{9}{|l|}{ Cerebral cortex } \\
\hline Layer I & - & 1 & - & 2 & - & - & - & - \\
\hline Layer II/III & - & 3 & 4 & 2 & - & 1 & 3 & 4 \\
\hline Layer IV & - & 3 & 3 & 2 & - & - & 3 & 2 \\
\hline Layer V & - & 3 & 4 & 2 & - & - & 3 & 4 \\
\hline Layer VI & - & 3 & 4 & 2 & - & - & 3 & 3 \\
\hline \multicolumn{9}{|l|}{ Hippocampus } \\
\hline CA1 (pyramidal cells) & - & 2 & 4 & 2 & - & 1 & 3 & 5 \\
\hline CA2 (pyramidal cells) & - & 1 & 1 & 2 & 5 & 1 & 3 & 5 \\
\hline CA3 (pyramidal cells) & - & 4 & 3 & 2 & - & 1 & 3 & 5 \\
\hline Dentate gyrus (granule cells) & - & 4 & 3 & 2 & 2 & 2 & 3 & 5 \\
\hline Interneurons & - & 3 & 3 & - & - & - & 3 & 4 \\
\hline Subiculum & - & 3 & 3 & 2 & - & 1 & 3 & 5 \\
\hline \multicolumn{9}{|l|}{ Striatum } \\
\hline Caudate-putamen & - & 3 & 4 & 4 & - & - & 2 & 4 \\
\hline Globus pallidus & - & 3 & 4 & 4 & - & - & 2 & 4 \\
\hline Septum & - & 3 & 3 & 3 & 4 & - & 2 & 4 \\
\hline Amygdala & - & 3 & 3 & 3 & 3 & - & 3 & 4 \\
\hline Corpus callosum & - & - & - & 2 & - & - & - & - \\
\hline Thalamus & - & 4 & 2 & 4 & 4 & - & 4 & 1 \\
\hline Hypothalamus & - & 4 & 3 & 4 & 2 & - & 4 & 3 \\
\hline Superior colliculus & - & 4 & 2 & 2 & 1 & - & 4 & 2 \\
\hline Inferior colliculus & - & 4 & 2 & 2 & 3 & - & 4 & 4 \\
\hline Substantia nigra & - & 3 & 2 & 2 & - & - & 3 & 2 \\
\hline \multicolumn{9}{|l|}{ Precerebellar nuclei } \\
\hline Pontine nuclei & - & 3 & 1 & 2 & - & - & 4 & 1 \\
\hline Reticulotegmental nucleus & - & 3 & 1 & 2 & - & - & 4 & 1 \\
\hline Lateral reticular nucleus & - & 3 & 1 & 1 & - & - & 4 & 1 \\
\hline Inferior olive & - & 2 & 2 & 1 & - & - & 4 & 1 \\
\hline $\begin{array}{l}\text { Motor nuclei*2 } \\
\quad 1\end{array}$ & & - & 4 & 1 & 1 & 1 & - & 4 \\
\hline Trigeminal nucleus (sensory) & - & 2 & 1 & 1 & - & - & 4 & 1 \\
\hline Cochlear nucleus (dorsal) & - & 3 & 1 & 1 & 1 & - & 4 & 1 \\
\hline \multicolumn{9}{|l|}{ Cerebellum } \\
\hline Purkinje cells & - & 5 & - & - & - & - & 5 & - \\
\hline Granule cells & - & 5 & 1 & 1 & - & - & 4 & - \\
\hline Stellate/Basket & - & 3 & 4 & 3 & - & - & 3 & - \\
\hline Bergmann glia & - & - & - & 4 & 4 & - & - & - \\
\hline Deep cerebellar nuclei & - & 3 & 1 & 1 & - & - & 4 & - \\
\hline
\end{tabular}


${ }^{1}$ Relative expression levels were estimated by visual comparison using both X-ray film autoradiograms and emulsion-dipped sections. -, not detected; 1 , very low; 2 , low; 3 , moderate; 4, high; 5 , very high. $*^{2}$ Trigeminal motor nucleus, facial nucleus, and hypoglossal nucleus. 